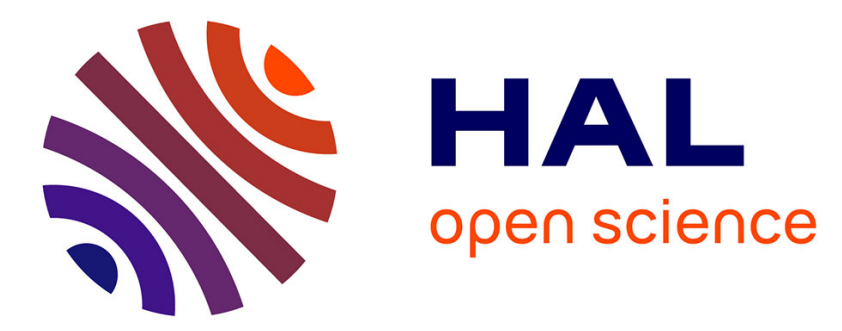

\title{
MOCVD Routes to \\ Tl2Ba2Can-1CunO4+2nSuperconductor and Dielectric Insulator Thin Films
}

\author{
B. Hinds, D. Studebaker, Jie Chen, R. Mcneely, B. Han, J. Schindler, T. \\ Hogan, C. Kannewurf, T. Marks
}

\section{To cite this version:}

B. Hinds, D. Studebaker, Jie Chen, R. Mcneely, B. Han, et al.. MOCVD Routes to Tl2Ba2Can1CunO4+2nSuperconductor and Dielectric Insulator Thin Films. Journal de Physique IV Proceedings, 1995, 05 (C5), pp.C5-391-C5-406. 10.1051/jphyscol:1995546 . jpa-00253908

\section{HAL Id: jpa-00253908 https://hal.science/jpa-00253908}

Submitted on 1 Jan 1995

HAL is a multi-disciplinary open access archive for the deposit and dissemination of scientific research documents, whether they are published or not. The documents may come from teaching and research institutions in France or abroad, or from public or private research centers.
L'archive ouverte pluridisciplinaire HAL, est destinée au dépôt et à la diffusion de documents scientifiques de niveau recherche, publiés ou non, émanant des établissements d'enseignement et de recherche français ou étrangers, des laboratoires publics ou privés. 


\title{
MOCVD Routes to $\mathrm{Tl}_{2} \mathrm{Ba}_{2} \mathrm{Ca}_{n-1} \mathrm{Cu}_{n} \mathrm{O}_{4+2 n}$ Superconductor and Dielectric Insulator Thin Films
}

\author{
B.J. Hinds, D.B. Studebaker, J. Chen, R.J. McNeely, B. Han, J.L. Schindler, T.P. Hogan, \\ C.R. Kannewurf and T.J. Marks
}

Northwestern University, Dept. of Chemistry, 2145 Sheridan Rd., Evanston IL. 60208-3113, U.S.A.

\begin{abstract}
The evolution of HTS device technologies will benefit firom the development ol MOCVD (Metal-organic Chemical Vapor Deposition) routes to high quality HTS lilms as well as to those of insulators with low dielectric loss and close HTS lattice matches. Reviewed here are research efforts at precursor design focusing on Ba sources. A novel low pressure TGA technique is used to compare volatilities of MOCVD precursors and to quantify the role of gas: phase diffusion in film growth. To form high quality $\mathrm{Tl}_{2} \mathrm{Ba}_{2} \mathrm{Ca}_{n-1} \mathrm{Cu}_{n} \mathrm{O}_{4+2 n} \quad(n=2.3)$ films.

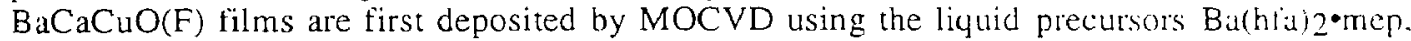
$\mathrm{Ca}(\mathrm{hfa}) 2 \bullet t e t$, and solid $\mathrm{Cu}(\mathrm{dpm})_{2}$ (hfa $=$ hexafluoroacetylacetonate, $\mathrm{lpm}=$ dipivaloylmethanate. mep $=$ methylethylpentaglyme, tet $=$ tetraglyme). The film growth process is shown (o he masi transport-limited, and an interesting ligand exchange process is identified. The superconductun: $\mathrm{TBCCO}$ phase is formed following an ex-situ anneal in the presence of $\mathrm{Tl}_{2} \mathrm{O}$ at temperatures from $820-900^{\circ} \mathrm{C}$. Transport properties of TBCCO-2223 films include a $T_{C}$ as high as $115 \mathrm{~K}$. $J_{C}$ of $2 \times 10^{5} \mathrm{~A} / \mathrm{cm}^{2}(77 \mathrm{~K})$, and $\mathrm{R}_{S}$ of $0.35 \mathrm{~m} \Omega(5 \mathrm{~K}, 10 \mathrm{GHz})$. The MOCVD growth of low loss. lattice-matched dielectric $\mathrm{NdGaO}_{3}, \mathrm{PrGaO}_{3}, \mathrm{Sr}_{2} \mathrm{AlTaO}_{6}$, and $\mathrm{SrPrGaO}_{4}$ films is also discussed. High quality $\mathrm{YBa}_{2} \mathrm{Cu}_{3} \mathrm{O}_{7-\mathrm{x}}$ films have been grown upon MOCVD-derived $\mathrm{PrGaO}_{3}$ substrates.
\end{abstract}

\section{INTRODUCTION}

The discovery of high temperature superconducting (HTS) oxides promises the realization of many novel thin film device concepts. Among these are Josephson junction-based devices for highly sensitive magnetic field detection or ultra-fast computation.[1] Due to the inherently low surface resistance. passive microwave devices such as filters and delay lines are other important applications of HTS materials.[2] Many of these HTS-based devices also require insulating, lattice-matched. low-loss dielectric oxide films. To fabricate such devices on a large scale, an efficien method to produce highquality thin films of oxide superconductors and dielectrics must he developed. MOCVD has many important attractions in terms of ability to coat large areas with high throughput under highly oxidizing conditions. However, the MOCVD technique also offers many challenges. These include the synthesis and characterization of suitably volatile precursors, understanding precursor decomposition and crystal growth mechanisms, and efficient reactor design. Of particular interest here is the growth of the TlBaCaCuO family of superconductors which have among the highest known critical temperature $1125 \mathrm{~K}) .131$ The growth of these materials by MOCVD presents the challenge of linding a suitahl: rolatik harium source and understanding the complex phase relationshins of the TIBaCaCuO TBCCO. 
family of superconductors. Presented here are the efforts to: 1) Develop suitably volatile alkaline and rare earth precursors. 2) Characterize their volatility and vapor pressure temporal stability with a novel reduced pressure thermogravimetric analysis. 3) Characterize the MOCVD growth process for $\mathrm{BaCaCuO}(\mathrm{F})$ thin fïlms. 4) Grow high quality $\mathrm{Tl}_{2} \mathrm{Ba}_{2} \mathrm{Ca}_{n-1} \mathrm{Cu}_{n} \mathrm{O}_{\mathrm{x}}$ thin films in a post annealing process and characterize transport and microwave properties. 5) Grow high quality lattice-matched dielectrics hy MOCVD for use with HTS materials.

\section{EXPERIMENTAL}

\subsection{Metal-organic precursor synthesis and TGA characterization}

$\mathrm{Ba}(\mathrm{hfa})_{2} \bullet \mathrm{mep}, \mathrm{Ca}(\mathrm{hfa})_{2} \bullet$ tet, and $\mathrm{Cu}(\mathrm{dpm})_{2}(\mathrm{hfa}=$ hexafluoroacetylacetonate, dpm = dipivaloylmethanate mep $=$ methylethylpentaglyme, tet $=$ tetraglyme) are prepared as described in the literature. $[4]$ $\mathrm{Ba}(\mathrm{dpm})_{2}$ is synthesized anhydrously from the reaction of $\mathrm{Ba}$ metal with Hdpm in THF solution. To measure the relative volatilities, sublimation rates of precursors were measured in a TA Instruments STD simultaneous thermogravimetric-differential thermal analysis (TGA-DTA) apparatus. The TGA-DTA directs a horizontal carrier gas tlow across $3.4 \mathrm{~mm}$ deep alumina sample pans mounted on microbalance arms. Pressure is adjusted by $\mathrm{N}_{2}$ flow rate $(50-100 \mathrm{sccm})$ and by a throttle valve in the connection to the 14 CFM direct drive pump.

\subsection{MOCVD growth}

The research MOCVD reactor used in this study (Figure 1) is of a straightforward horizontal design, and details are described elsewhere.[5,6] Metal-organic precursor reservoirs are individually heated in thermostated oil baths, and carrier flows are mixed in a common manitold. To aid in uniformity of deposition rate, a quartz laminar flow chamber is utilized. The 3:1 aspect ratio of width-to-height in this flow chamber reduces thermal buoyancy effects, thus enhancing the stability of carrier flow.[7] A SiCcoated graphite susceptor is positioned at the end of the flow chamber and is angled at $8.7^{\prime \prime}$ to aid uniformity of deposition along the length of the substrate. The susceptor is heated hy a $6 \mathrm{~kW}$ water-

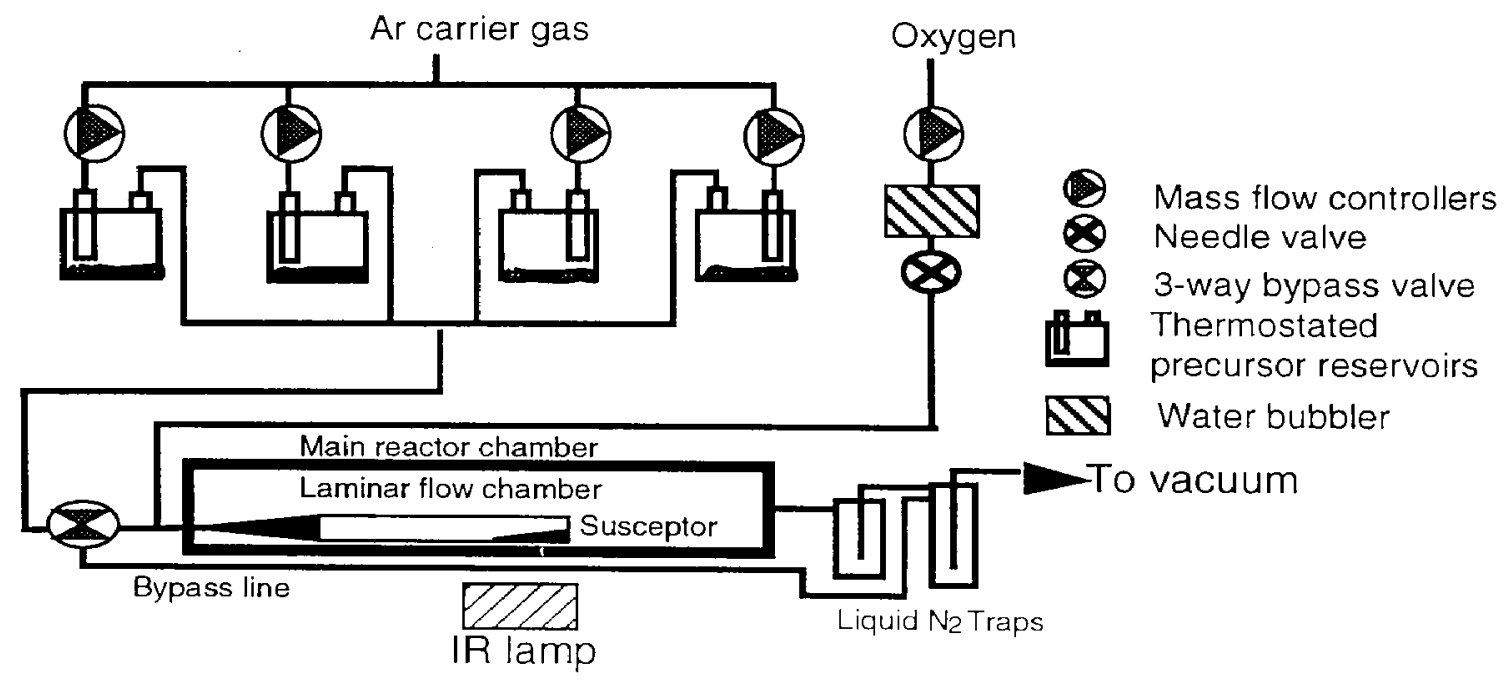

Figure 1. Schematic of research MOCVD reactor. 
cooled IR lamp, and temperature is monitored by a K-type thermocouple on the surface of the susceptor Pressure is controlled by throttle valve. To find stoichiometry and deposition rates, the metal content ol films is determined using an AtomScan $25 \mathrm{ICP}$ atomic emission spectrometer. In the hyproduct trapping study, a $0^{\circ} \mathrm{C}$ trap is placed on the bypass line $10 \mathrm{~cm}$ downstream from the hypass valve. A small tuhe furnace, at 400$)^{\circ} \mathrm{C}$, is placed around the bypass line between the trap and hypass valve. Oxidiger is introduced at the common precursor manifold.

\section{$2.3 \mathrm{Tl}_{2} \mathrm{Ba}_{2} \mathrm{Ca}_{n-1} \mathrm{Cu}_{n} \mathrm{O}_{4}+2 \mathrm{n}$ phase formation}

Due to the high volatility and extreme reactivity of $\mathrm{Tl}_{2} \mathrm{O}$, it is difficult to grow films in an in-siru process (i.e., one not requiring a post-anneal). MOCVD derived $\mathrm{BaCaCuO}(\mathrm{F})$ films are thus reacted with an equilibrium pressure of $\mathrm{Tl}_{2} \mathrm{O}$ from a bulk $\mathrm{TBCCO}$ superconductor pellet of maintained at temperatures between $820-9000^{\circ} \mathrm{C}$. The pellet is prepared from presintered $\mathrm{Tl}_{2} \mathrm{O}_{3}, \mathrm{BaO}, \mathrm{CaO}, \mathrm{CuO}$ powders with cation ratios of 2212 or 2223 . The film is supported face down over the pellet with gold toil and sealed in a crimped gold foil crucible to minimize $\mathrm{Tl}_{2} \mathrm{O}$ loss. The atmosphere of the furnace is purged with purified $\mathrm{O}_{2}$ or $1\left(1 \% \mathrm{O}_{2} / \mathrm{Ar} \text { before the crucible is sealed. The temperature is ramped slowly at } 2^{\circ} \mathrm{C} / \mathrm{min} \text { (1) } 7(0)\right)^{\circ} \mathrm{C}(1)$ drive off any absorbed water, then quickly ramped $\left(20^{\circ} \mathrm{C} / \mathrm{min}\right)$ to reaction temperaturc. Hold times vary from (). 3 to $15 \mathrm{~h}$.

\subsection{Thin film characterization}

$X$-ray diffraction data were collected with a Rigaku DMAX-A diffractometer using Ni-filtered Cu $\mathrm{K}_{\alpha}$ radiation. Film thickness was measured by a Tencor P10 profilometer. Fluorine content was monitored by Hitachi 4500 SEM using Cambridge Scientific EDX analysis with light element window. Magnetic susceptibility measurements were made using a Quantum Design SQUID. $T_{c}$ and $J_{c}$, on $80 \mu m$ wide patterned bridges, were measured using the 4-point probe instrumentation described elsewhere.[8]

\section{DISCUSSION}

\subsection{Precursor design}

Any efficient MOCVD process relies critically on the availability of high purity metal-organic precursors with high, stable vapor pressures. An important approach to realizing such precursors is to minimi $x^{\circ}$ molecular oligimerization by saturating the metal coordination sphere with sterically hindered and/or fluorinated ligands. Of equal importance is that the precursor has suitable reactivity at deposition temperatures without prior gas phase decomposition. Until the discovery of HTS materials, the development of alkaline and rare earth metal MOCVD precursors had been largely neglected.

Generally, the four classes of volatile metal compounds are organometallic, halide, alkoxide, and coordination compounds (such as $\beta$-diketonates). Volatile organometallic compounds of alkaline and rare earth metals are known, however they tend to be extremely oxygen-sensitive. rendering transport in an oxidative environment difficult. Halide CVD has been utilized in HTS malerials, however difliculties exist in transporting the relatively nonvolatile halides and in adjusting the themodynamics to lorm oxides.[9] Alkoxides are utilized in the growth of oxide thin films fsuch as BaTiOz with

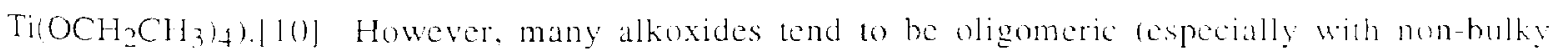
ligands), have low vapor pressures, and are air sensitive. B-diketonates form complexes with most metak 
A.

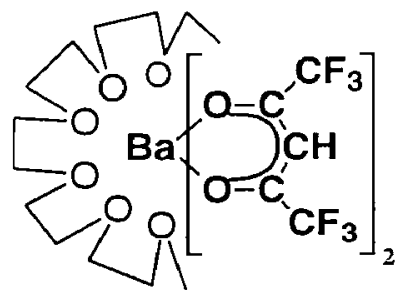

B.

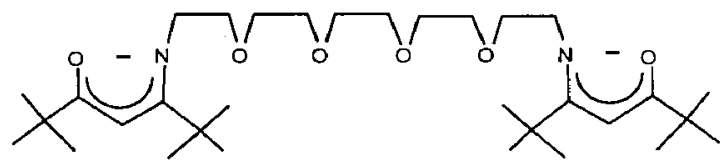

Figure 2A. Ba(hfa) $2^{\bullet}$-mep, a stable liquid barium precursor used in this study for the growth of TBCCO thin films. B. Novel ketoiminate ligand forming a readily sublimable $\mathrm{Ba}$ complex. and offer great versatility in chemical modification. One strategy for modification is to use the sterically encumbered $t$-hutyl group in the dipivaloylmethanate (dpm, 1,1,6,6tetramethylheptane2,4dionate or (mhd) ligand. However, with electropositive metals having large ionic radii, the dpm ligand is not effective in reducing lattice oligomerization. Thus, dpm complexes of $\mathrm{Ba} . \mathrm{Sr}$ and La have low volatilities. To achieve suitable vapor pressures these dpm compounds must be healcd to near the respective decomposition temperatures, resulting in unstable vapor pressure characteristics and unreliable CVD processes. In particular, a stable precursor for

Ba would he highly desirable.

To reduce lattice cohesive energies, large bulky fluorinated ligands can he used. Bis(tetradecafluorononanedionato)aquobarium(II), Ba(tdfnd) $)_{2} \cdot \mathrm{H}_{2} \mathrm{O}$, had been employed for the grow'th of $\mathrm{BaF}_{2}$ films at a source temperatures $40^{\circ} \mathrm{C}$ less than typically used for $\mathrm{Ba}(\mathrm{dpm})_{2} .[11]$ Another very attractive strategy is to use the electron withdrawing ability of fluorinated ligands to promote the coordination of neutral, electron-rich, ancillary ligands, thus further saturating the metal coordination sphere. Meinema, et al. employed a coordinated polyether around the $\mathrm{Ba}^{2+} \mathrm{ion}$ in $\mathrm{Ba}(\mathrm{hta})_{2} \cdot \mathrm{tet}$.| $12 \mid$ They found that the compound sublimes as a monomer at temperatures 100$)^{\circ} \mathrm{C}$ less than $\mathrm{Ba}(\mathrm{dpm})_{2}$. This technique has been similarly applied in the Ba(tdind) 2 system with the coordination of tetraglyme.|13| Of particular importance here is the low melting point of this compound. A liquid precursor climinates vapor pressure instabilities that can arise from varying surface area of powders due to sintering effects. Another approach to lowering the precursor melting point is to modify the coordinating polycther. Using unsymmetric polyethers, Neumayer, et al. developed volatile $\mathrm{Ba}\left(\mathrm{h} \mathrm{f}^{\prime}\right)_{2} \bullet$ methylhutylhexaglyme with it melting point as low as $52^{\circ} \mathrm{C}$.[14] The related $\mathrm{Ba}(\mathrm{hfa})_{2} \bullet$ mep (mep = methylethylpentaglyme) (Figure $2 \mathrm{~A}$ ) has a melting point of $110^{\circ} \mathrm{C}$ and is used as a liquid Ba source in the present study of TBCCO growth.

A disadvantage of the fluorinated precursors is that at deposition temperatures $01^{\circ} 350-78()^{\prime \prime} \mathrm{C}$. tluorides are incorporated in the growing film from decomposing ligands. However, without the electron-withdrawing fluorinated ligands, polyethers do not form stable complexes. An alternative approach is to attach polyethers directly to the $\beta$-diketonate ligand to stabilize the coordination of the polyether. Work in this laboratory used polyethers attached to ketoiminate ligands and demonstrated useful volatility in this class of complexes for the growth of $\mathrm{BaPhO}_{3}$ films hy MOCVD. A relitcd compound with the polyether spanning two $\beta$-ketoiminate ligands has also been recently synthesized (Figure 2B). The crystal structure shows the compound to be coordinately saturuted.| $16 \mid$ 


\subsection{Reduced pressure thermogravimetric analysis}

In order to have a controlled MOCVD process, the vapor pressures of the metal-organic precursurs must he horoughly characterized. However, many HTS metal-organic precursors have relatively low valpor pressures (<0.2 Torr under usual deposition conditions) which makes vapor pressure measurement difficult. To study vapor pressures in the $10^{-9}$ to $10^{-4}$ Torr range, it is possible to use high vacuum evaporation rates combined with the Knudsen-Langmuir equation. For vapor pressures greatir that 5 Torr, it is possible to use either transpiration methods or to measure the hoiling point directly. Tu measure vapor pressures between $10^{-4}$ and 5 Torr, the pressure must he directly measured with a manometer using a rigorously sealed and evacuated chamber.[17] This method can encounter greal experimental difficulties due to the formation of decomposition products and other volatile impuritics. With great care, reliable data can be obtained.[18] However, data descrihing diffusion of MOCVD precursors cannot be acquired using this method. Under typical MOCVD conditions, total system pressures range from 1 to 20 Torr and non-equilibrium diffusion effects can be significant. A useful technique is to measure the evaporation rate of a precursor using thermogravimetric andysis (TGA) techniques under reduced pressure. From this dynamic procedure, information concerning uperational vapor pressure and diffusion can be obtained.

The evaporation rate in high vacuum relates to equilibrium vapor pressure hy the KnudsenLangmuir equation,[19]

$$
j=\alpha P_{E}(M / 2 \pi k T)^{1 / 2}
$$

where $\mathrm{j}$ is the evaporation rate per unit area, $\alpha$ is the condensation coefficient, $\mathrm{P}_{\mathrm{E}}$ is the equilibrium partial pressure, $M$ is the molecular weight, $k$ is the Boltzman constant, and $T$ is temperature. At higher pressures of inert gas, diffusion effects become important. The Langmuir equation hecomes.

$$
\mathrm{j}=\frac{\alpha\left(\mathrm{P}_{\mathrm{E}}-\mathrm{P}_{\mathrm{x}}\right)(2 \pi \mathrm{MkT})^{-1 / 2}}{1+\alpha(\mathrm{x} / \mathrm{D})(\mathrm{kT} / 2 \pi \mathrm{M})^{1 / 2}}
$$

where $P_{x}$ is the pressure of the compound at distance $x$ from the surliace, and $D$ is the ditifusion coefficient. At the limit of high total pressures (small D), this becomes Fick's first law of diffusion.

There are several examples of reduced pressure TGA being used to study the volatility of MOCVD precursors. Takahashi, et al. used the classic Langmuir relation to describe the volatility of organic monomers for use in vapor deposition polymerization.[20] They note a sublimation ralc decuase with increasing total pressure, which they attribute to a pressure dependent $\alpha$ lerm in ey.(1). At the lowest altained total pressure of $10^{-4}$ Torr, they assumed $\alpha=1$ to calculate the equilibrium vapor pressures. However, the assumption of $\alpha=1$ is not generally valid, and $\alpha$ cun vary hy several orders of magnitude for organic powders.[17] Suictly speaking, $\alpha$ is independent of inert gas pressure and cannou be measured for undefined powder surfaces without knowledge of equilibrium vapor pressure. The observed decrease in evaporation rate with total pressure is more likely diffusion-dependent, as descrihed hy eq. (2). Chou, et al., measured the dynamic evaporation rates of $\mathrm{Ba}(\mathrm{dpm})_{2}, \mathrm{Ca}(\mathrm{dpm})_{2}, \mathrm{Cu}(\mathrm{dpm})_{2}$ at 20 Tor lotal pressure, which is near typical low pressure MOCVD conditions. (21) They reported a decrease in suhlimation rate with time which they attributed to sintering and change in height of the precursors in the sample pans. Due to ambiguity in sample preparation in relation to sample height and area, diftusion

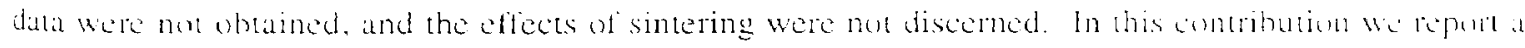
simple reduced pressure TGA experiment that allows measurement of the product of the dillusun 

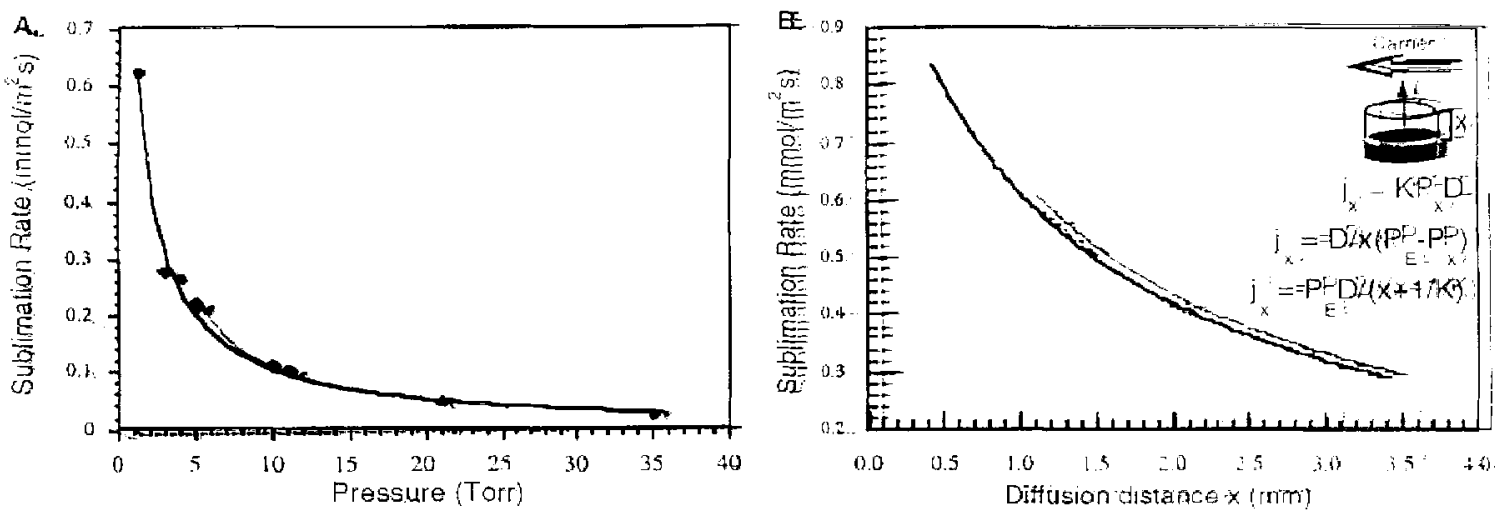

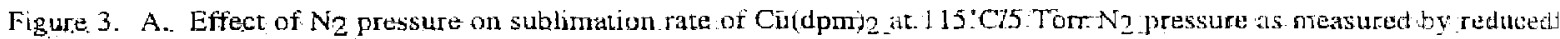
pressure TGA. Under typical MOCVD conditions., diffusion effects dommate precursor transport: B! Sublimationtrate-ut $\mathrm{Cu}(\mathrm{dpm}) 2$ at $120^{\circ} \mathrm{C} 5$. Tor $\mathrm{N}_{2}$ pressure as a function of diffusion:distance $\mathrm{x}$. Diffusan distance; $\mathrm{x}$. is calculated firom

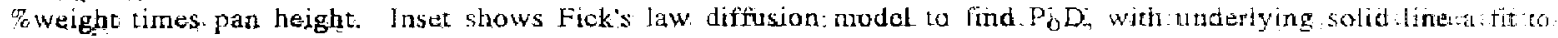
experimental data:

coefficient times the equilibrium vapor pressure of MOCVD precursors. This ailows for a controlledt comparison of precursor volatility in the MOCVD environment. With the equilibrium vapor pressureat: the compound known, the diffusion coefficient can be calculated.

The rate of sublimation in a TGA experiment is calculated from the derivative of weight avith: respect to in divided by molecular weight and the area of the crucible. Figure $3 \mathrm{~A}$. shows that for representative $\mathrm{Cu}(\mathrm{dpm})_{2}$, the rate of evaporation is significantly reduced as the anbient presslure is increased, which indicates that diffusion is a limiting factor in the transport of these precursors. Witti diffusion effects being important under these conditions, the distance that the precursor nust thvel from the surface of the powder 10 the top of the crucible is a significant factor. Figure 3 Bi shows tha evaporation rate as a function of distance from the solid precursor surface to the edge of the trucible-(x:= weight/full-weight $x$ crucible height). Over a distance of $3.4 \mathrm{~mm}$, a 3 -fold decrease in sublimation rate-is seen at 5 Torr total pressure; The same reduction in evaporation rate is seen for liquid preeursors at: similar volatility, thus sintering over time is not the dominant cause of volatility reduction... To madel the sublimation, rate, note that the measured weight loss rate is the flux of precursor from the top of the pam into the carrier stream $\left(\mathrm{j}_{\mathrm{x}}\right)$. We assume that this rate is proportional to the pressure of precursor at the plane on top of the pan $\left(P_{x}\right)$ and to the diffusion coefficient (D) (eq.(3)),

$$
\mathrm{j}_{\mathrm{X}}=\mathrm{KD} \mathrm{P}_{\mathrm{X}}, \quad \mathrm{P}_{\mathrm{x}}=\mathrm{j}_{\mathrm{X}} / \mathrm{KD}
$$

where $\mathrm{K}$ is a constant dependent on the geometry of the crucible surface with respect to the canter stream At slow temperature ramp razes, steady-state conditions exist, and $j_{x}$ is equal to the the of precursor from the surface of the powder to the top of the pan. This flux is described by Fich's lirst latw of ditlusiom (eq.(4)). Substituting. $P_{x}$ from (3) into (4) yields (5),

$$
j_{x}=\frac{D}{X}\left(P_{E}-P_{x}\right)=\frac{D}{X}\left(P_{E}-\frac{j x}{K D}\right)
$$




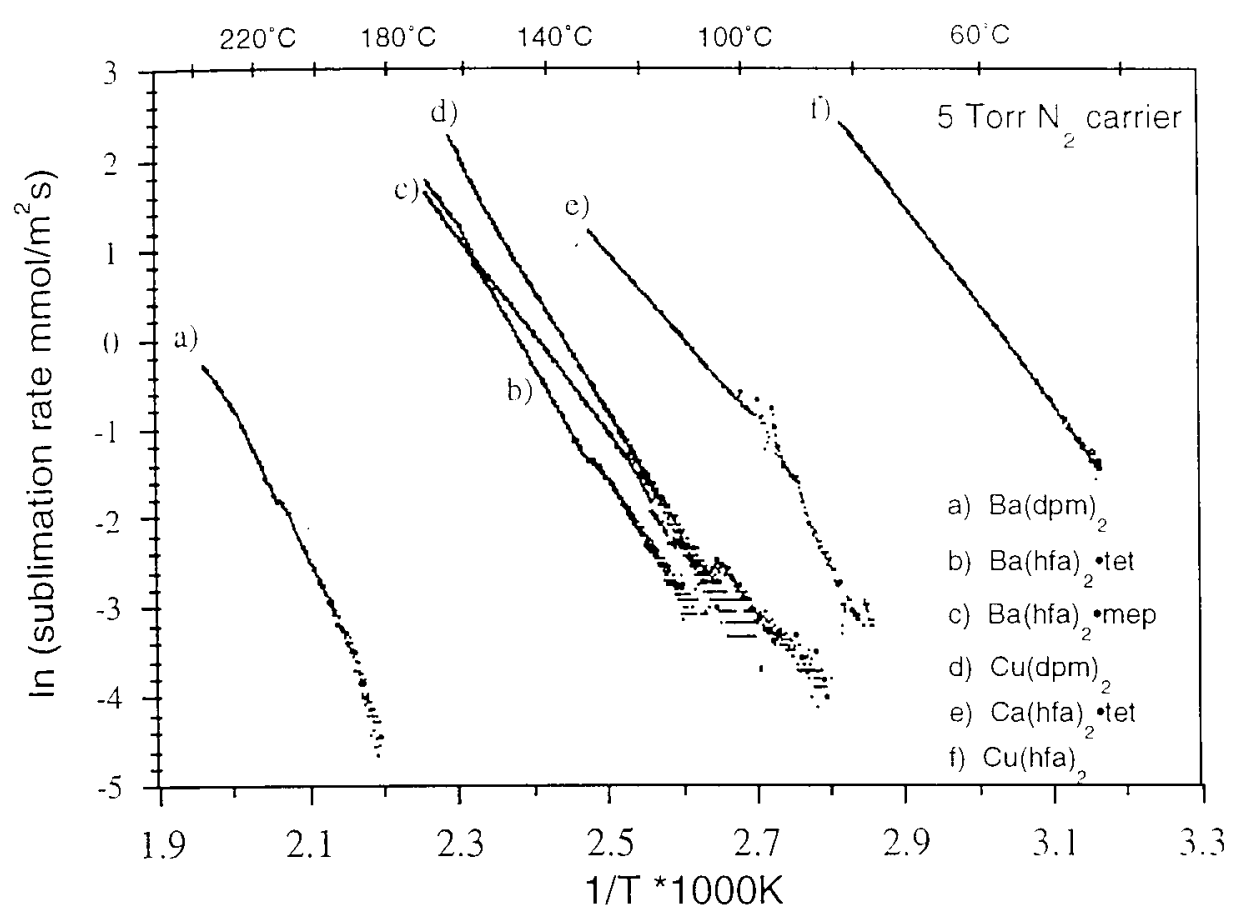

Figure 4. Comparison of volatilities of six HTS MOCVD precursors determined by reduced pressure TGA. Conditions: 5 Torr total pressure: $\mathrm{N}_{2}$ flowing at $100 \mathrm{sccm}$; temperature ramp rate of $1.5^{\circ} \mathrm{C} / \mathrm{min}$. Sublimaton rates ate nomalized 10 at diffusion distance of $1.7 \mathrm{~mm}$. Inflection points show melting points of the various precursors.

where $P_{E}$ is the equilibrium vapor pressure of the precursor at the surface of the powder and $x$ is the distance from the powder surface to the top of the pan. A two parameter curve fit of experimental jx lis. $x$ yields the product $D P_{E}$ and $K$. Unfortunately, this single experiment cannot separate vapor pressure and diffusion effects. Since the equilibrium vapor pressure of $\mathrm{Ba}(\mathrm{hta})_{2} \cdot \mathrm{tet}$ is known from direct manometric measurements, [18] the resulting diffusion coefficient calculated from $\mathrm{PED}_{\mathrm{E}}$ is $1.5 \times 10^{4} \mathrm{~m}^{2} / \mathrm{S}$ at $115^{\prime \prime} \mathrm{C}, 5$ Torr $\mathrm{N}_{2}$. Thus, it can be seen that a boundary layer of several millimeters from precursor surface (1) carrier stream can have dramatic effects on the evaporation rate. From these reduced pressure TGA experiments, it is readily apparent that diffusion plays a dominant role in the transport of the metalorganic precursors. This is of particular importance when designing transport evaporators far an MOCVD reactor. These effects can also be seen in the slopes of Arrhenius plots of the ln(sublimation rate) vs. $1 / \mathrm{T}$ for $\mathrm{Ba}(\mathrm{hfa})_{2} \bullet$ tet which yield activation energies for the sublimation process. At total $\mathrm{N}_{2}$ pressures of 6.0 Torr, the activation energy for $\mathrm{Ba}(\mathrm{hfa})_{2} \bullet$ tet vaporization is $1.70 \mathrm{~kJ} / \mathrm{mol}$ : at $4.0 \mathrm{~T}$ (orr, 1.50$)$ $\mathrm{kJ} / \mathrm{mol}$; and at 0.1 Torr $1.23 \mathrm{~kJ} / \mathrm{mol}$. These data can be compared to the enthalpy of vaporization of 1.08 $\mathrm{kJ} / \mathrm{mol}$ from the equilibrium vapor pressure data.[18] As the diffusion coefficient is generally descrihed to be thermally activated, the activation energy for the sublimation process would he expected to be the sum of the vaporization enthalpy and diffusion activation energy terms. Since the sublimation rate is strongly dependent on diffusion, equilibrium vapor pressure data alone cannot he used to find the optimal lemperature for a given transport rate. Typically, for precursor transport, the conditions of flow ratc. pressure, and temperature must be empirically determined for a given evaporator geometry. 


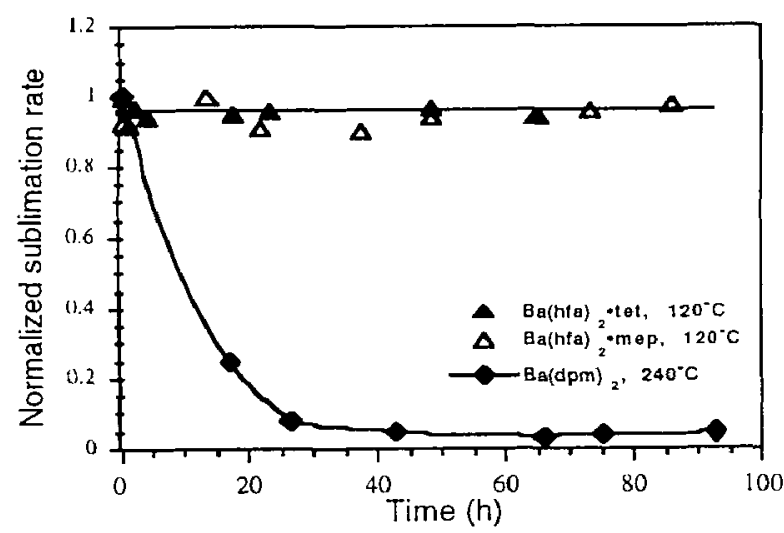

Figure 5. Vapor pressure temporal stability of important $\mathrm{Ba}$ MOCVD precursors at film growth temperatures. Sublimation rate is measured at 5 Torr $\mathrm{N}_{2}$. Between points, the TGA is backfilled with 1 atm $N_{2}$, where the sublimation rate is negligible. The commonly used $\mathrm{Ba}(\mathrm{dpm})_{2}$ temporal stability is poor compared to the fluorinated precursors.

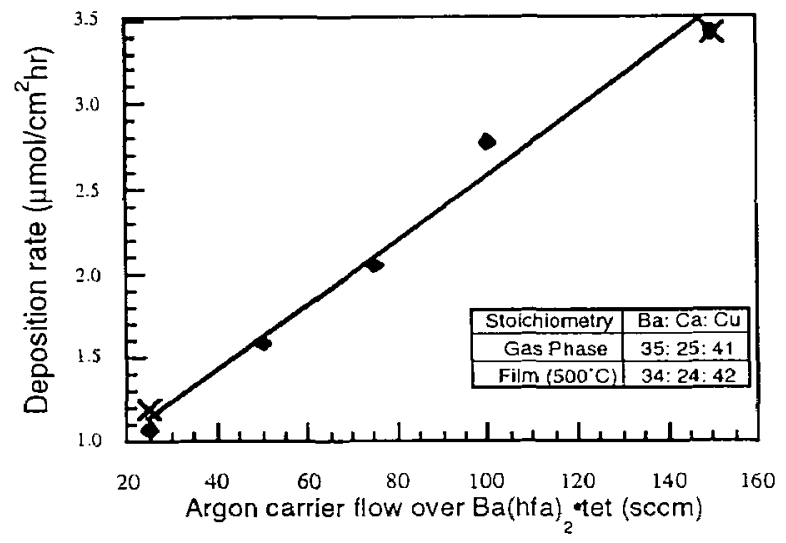

Figure 6. Growth rate of $\mathrm{BaO}(\mathrm{F})$ films as a function of carrier gas flow rate through the $\mathrm{Ba}(\mathrm{hfa})_{2} \cdot$ mep precursor reservoir. Conditions: 5 Torr total pressure; $350 \mathrm{sccm} \mathrm{O}_{2} / \mathrm{H}_{2} \mathrm{O}$ oxidizer; total flow $500 \mathrm{sccm}$ with Ar dilution; 500 $\mathrm{C}$ substrate temperature. Cross hatches show the relative precursor weight Ioss at 25 and $150 \mathrm{sccm}$ carrier flow. Inset shows gas phase stoichiometry during film growth as measured by precursor weight loss. $\mathrm{BaCaCuO}$ film stoichiometry is measured by ICP atomic emission spectroscopy.

various precursors under MOCVD film growth conditions. At typical MOCVD pressures, diffusion effects are substantial and reactor design must reflect this. Fluorinated harium polyether adduct precursors are demonstrably more volatile and stable for MOCVD film growth.

\subsection{Growth of $\mathrm{BaCaCuO}(\mathrm{F})$ thin films}

The MOCVD process is complex and can be described in the following steps: 1) volitilization of the precursor into the carrier stream, 2) transport of the precursor to the hot reaction zone. 3) surliace absorption of the precursor and other reactive species, surface migration, and decomposition, f) surface 
migration and formation of the crystalline solid film, and 5) removal of the organic by-products. In many MOCVD processes, the second step is known to be rate-limiting, and reactor design considerations. provide a constant supply of gaseous precursor over the area of the deposition zone. As descrithed in the Experimental Section, the present MOCVD reactor design is employed to provide a uniform supply of precursor over a large substrate area. To determine whether the film growth rate is limited hy mass transport effects, it is necessary to elucidate the relationship of precursor partial pressure to deposition rate. Figure 6 shows that as the carrier flow through the precursor reservoir is increased from 25 in 150 ) sccm (with constant total carrier flow) the deposition rate increases approximately linearly. Under conditions of constant total carrier flow rate, a doubling of the precursor tlow rate should ideally douhle the concentration of precursor in the carrier stream and hence double the deposition rate. However an

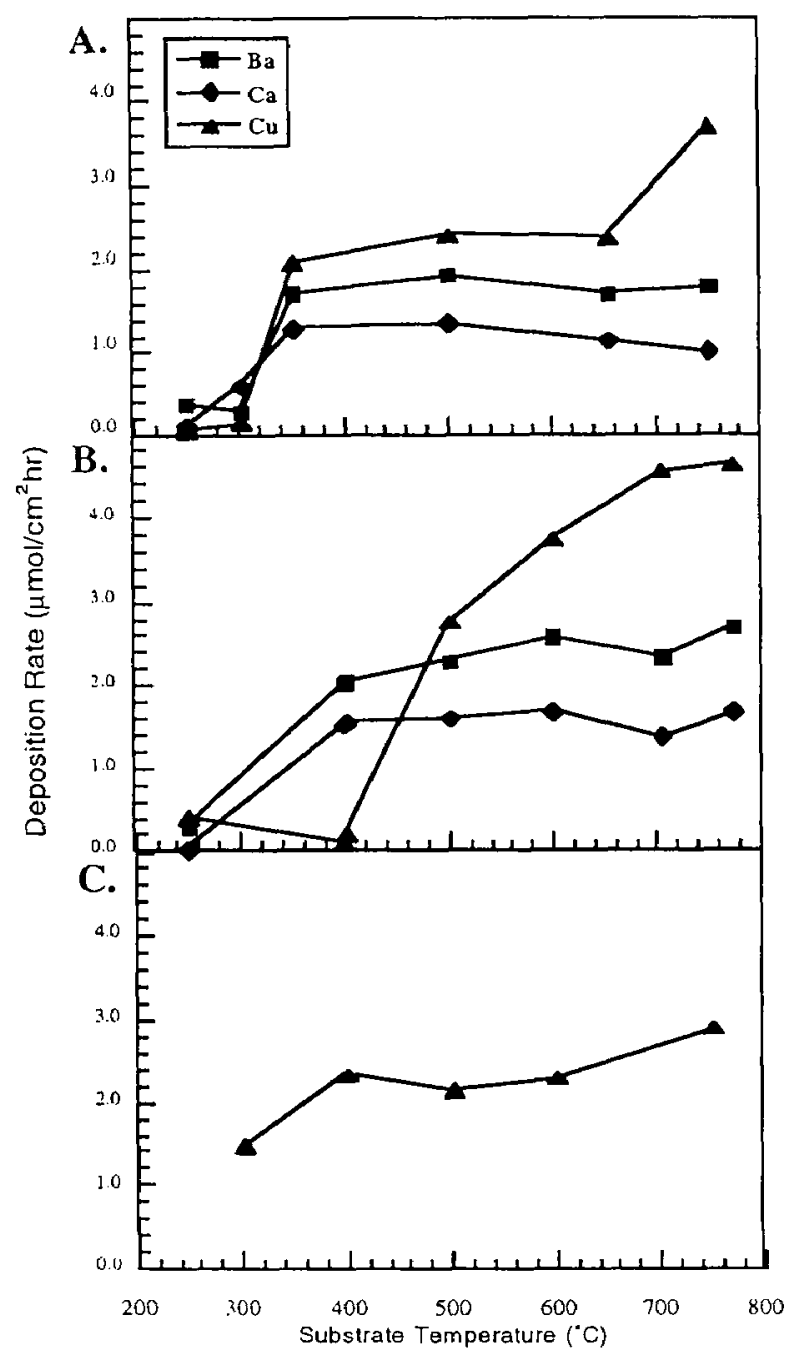

Figure 7. MOCVD deposition rate $v s$. substrate temperature for $\mathrm{BaCaCuO}$ thin films using $\mathrm{Ba}(\mathrm{hfa})_{2} \cdot \mathrm{mep}, \mathrm{Ca}(\mathrm{hfa})_{2} \bullet$ tet, $\mathrm{Cu}\left(\mathrm{d}_{\mathrm{pm}}\right)_{2}$ precursors. Conditions: 5 Torr total pressure; 350 scom oxidizer flow; $150 \mathrm{sccm}$ total Ar carrier flow. A) With $\mathrm{H}_{2} \mathrm{O}$ and $\mathrm{O}_{2}$ oxidizing stream. B) Only $\mathrm{O}_{2}$ oxidizer C) Only $\mathrm{O}_{2}$ oxidizer and $\mathrm{Cu}(\mathrm{d} \mathrm{m})_{2}$ precursor: increase in deposition rate by only a factor of 1.5 is seen when the precursor stream flow rate is doubled. With a diffusion limited sublimation rate, the precursor carrier gas will not reach saturation and higher flow rates will dilute the pressure of precursor. Hence the deposition rato should not be directly proportional to precursor flow rate. At flows much higher than 150, sccm (the maximum for the present apparatus), deviation from the observed linear relationship would be expected. Also of importance are tho crosshatched points in Figure 6 that show the relative precursor weight loss for precursors at the reservoir flow rates of 25 and 150 scem. Both the deposition rate and precursor rate increase hy a factor of 3.3. The deposition rate is directly proportional to precursor transport rate and hence to the precursor partial pressure in the total carrier stream, as expected for a mass transport-limited process.

As suggested hy the TGA experiments. the diffusion of the precursor into the carrier stream is a limiting factor in the sublimation rate and it would thus be difficult to achieve equilibrium precursor pressures in the carrier stream. From the precursor weight loss and carrier gas volume, the ideal gas law partial pressure of $\mathrm{Ca}(\mathrm{hta})_{2} \cdot \mathrm{te}$ is estimated to be $-0.0(0)$ Torr in the carrice stream. while equilibrium vapor pressure is near 0.2 Tort [18] Thus, the specilics of reservolr design in terms of diffusion distance are an importan 
factors for HTS MOCVD processes. If film growth is mass transport-limited, then the gas phase stoichiometry should be the same as that of the deposited film. The inset in Figure 6 shows that the gials phase stoichiometry as measured by precursor weight loss is identical to that of the deposited film ats measured by ICP.

To further demonstrate the mass-transport limited character of $\mathrm{BaCaCuO}$ growth, depusition rate versus substrate temperature data are shown in Figure 7. The precursors used werc Ba(hfia $)_{2} \bullet \mathrm{mcp}$. $\mathrm{Ca}(\mathrm{hfa})_{2} \bullet t e t$, and $\mathrm{Cu}(\mathrm{dpm})_{2}$, and the oxidizer stream was $\mathrm{O}_{2}$ and $\mathrm{H}_{2} \mathrm{O}$. It can he seen that a transportlimited growth regime begins at temperatures near $350^{\circ} \mathrm{C}$. This is interesting because for the MOCVD of $\mathrm{YBa}_{2} \mathrm{Cu}_{3} \mathrm{O}_{7}$ using non-fluorinated $\mathrm{Y}(\mathrm{dpm})_{3}, \mathrm{Ba}(\mathrm{dpm})_{2}, \mathrm{Cu}(\mathrm{dpm})_{2}$ precursors, a mass transport-limitcd regime was found at temperatures greater than $600^{\circ} \mathrm{C}$. [22] The decomposition of the hia ligands is apparently more facile, which is surprising in view of the fact that fluorinated ligands produce morc Lewis acidic metal centers which in turn form more stable adducts with the polyether glymes. Since the deposition rates here are similar to those observed in other studies $(\sim 20 \mathrm{~nm} / \mathrm{min})[22]$, the depression in the onset temperature for mass transport-limited kinetics is not due to a lower muss transport rate. In principle the effect of $\mathrm{H}_{2} \mathrm{O}$ on the decomposition reaction could be great since it could act as a proton source to form volatile Hhfa byproducts. To explore this possibility, the above experiment was conducted without water in the oxidizing stream. The same general results were observed with mass transport-limited deposition beginning near $400^{\circ} \mathrm{C}$ (Figure 7B). The deposition characteristics of $\mathrm{Cu}(\mathrm{dpm})_{2}$ under the conditions of Figure $7 \mathrm{~B}$ are markedly different. At $4010^{\circ} \mathrm{C}$, there is essentially no $\mathrm{Cu}$ deposition. A possible explanation is that the decomposition products of $\mathrm{Ba}(\mathrm{hfa})_{2} \bullet$ mep and $\mathrm{Ca}(\mathrm{hfa})_{2} \bullet \mathrm{icl}$ form $\mathrm{Cu}(\mathrm{hfa})_{2}$ which is then etched from the film. There is precedent for $\mathrm{Cu}(\mathrm{hfa})_{2}$ heing formed in the selective etching of $\mathrm{Pd} / \mathrm{Cu}$ surfaces.[23] The temperature vs. deposition rate plot for $\mathrm{Cu}(\mathrm{dpm})_{2}$ in Fisurc $7 \mathrm{C}$ shows a rather constant growth profile that gradually increases with temperature. This is consisicnt with the results of Schmaderer, et al. [22] which reveal a very shallow increase in CuO deposition rate from $4000^{\circ} \mathrm{C}-90\left(0^{\circ} \mathrm{C}\right.$. The diminution of $\mathrm{CuO}$ deposition at $400^{\circ} \mathrm{C}$ seen in Figure $7 \mathrm{~B}$ requires the presence of fluorinated precursors and the absence of $\mathrm{H}_{2} \mathrm{O}$. Note that in the experiment shown in Figure $7 \mathrm{C}$. metallic $\mathrm{Cu}$ deposits at lower temperatures from $\mathrm{Cu}(\mathrm{dpm})_{2}$ alone.

To test the hypothesis that copper can be etched from $\mathrm{BaCaCuO}(\mathrm{F})$ films as $\mathrm{Cu}(\mathrm{hfa})_{2}$, the volutile metal byproducts of $\mathrm{Ba}(\mathrm{hfa})_{2}{ }^{\bullet} \mathrm{mep}, \mathrm{Ca}(\mathrm{hfa})_{2} \bullet t e t, \mathrm{Cu}(\mathrm{dpm})_{2}$ codeposition were trapped at $0^{\prime \prime} \mathrm{C}$ shortly after passing the gaseous mixture through a resistively heated tube at $400^{\circ} \mathrm{C}$. The trapped solids were then analyzed by mass spectrometry. When the products of the MOCVD reaction at 40()$)^{\prime \prime} \mathrm{C}$ without $\mathrm{H}_{2} \mathrm{O}$ in the oxidizer stream (as in Figure 7B) were analyzed, both $\mathrm{Cu}(\mathrm{hfa})_{2}$ and $\mathrm{Cu}(\mathrm{hta})(\mathrm{dpm})$ were present under conditions where $\mathrm{CuO}$ etching was prevalent. However, when the products of the MOCVD reaction at

Table 1. Typical MOCVD growth conditions for $\mathrm{BaCaCuO}$ films having $2: 1: 2$ cation stoichiometry

\begin{tabular}{ll}
\hline Precursor bath temperatures & $116^{\circ}, 86^{\circ}, 112^{\circ} \mathrm{C}$ for $\mathrm{Ba}, \mathrm{Ca}, \mathrm{Cu}$ \\
Precursor carrier flow & $50-100 \mathrm{sccm}$ each \\
$\mathrm{O}_{2} / \mathrm{H}_{2} \mathrm{O}$ flow & $100 / 250 \mathrm{sccm}$ \\
Total pressure & $5 \mathrm{Torr}$ \\
Substrate temperature & $5\left(10^{\circ} \mathrm{C}\right.$ \\
Growh rate & $1.2 \mu \mathrm{m} / \mathrm{hr}$ \\
Substrate & $(110)$ single crystal $\mathrm{LaAlO}_{3}$ \\
\hline
\end{tabular}
$400^{\circ} \mathrm{C}$ with $\mathrm{H}_{2} \mathrm{O}$ in the oxidizer stream (as in Figure 7A) were analyzed. $\mathrm{Cu}(\mathrm{hfa})_{2}$ was also ohserved (withour CuO etching). Thus, ligand exchange is operative withoul simulaneous etching of $\mathrm{CuO}$. It is important to note that no Cu(htia) 2 is seen when the carrier stream is condensed without 


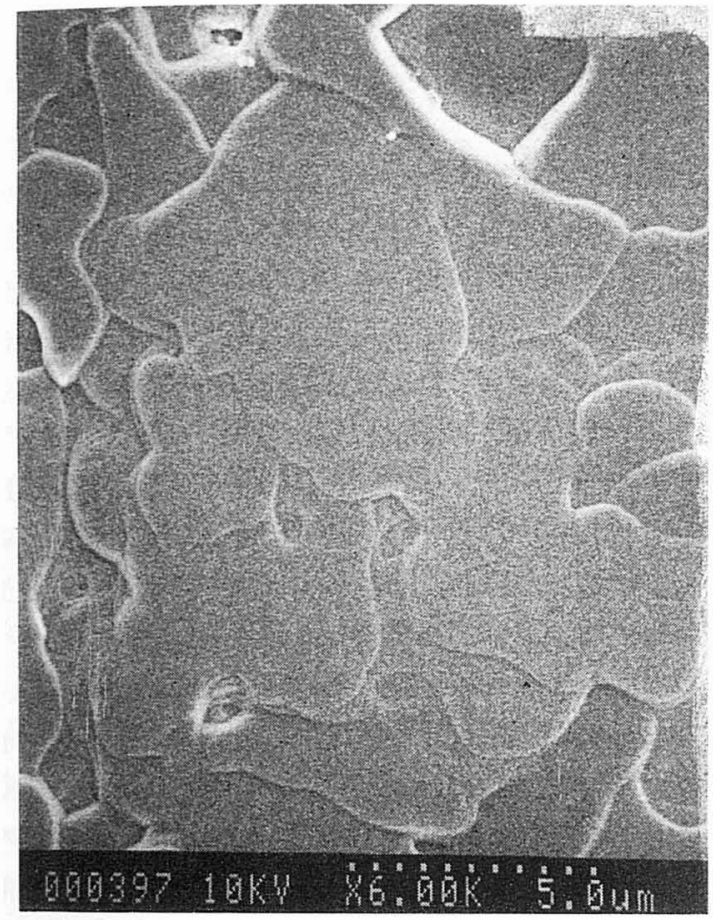

Figure 8. SEM micrograph of an MOCVD-derived TI-2212 film showing characteristic platelet morphology

passing through the heated reaction tone.

From the study ol deposition rate as a function of precursor transpont and substrate temperature, it is found that the general mechanism of $\mathrm{BaCaCuO}(F)$ MOCVD growth is mass transport-limited with the present precursor system. $\mathrm{H}_{2} \mathrm{O}$ in the oxidizer stream has little cliect on film growth rate. Ligand exchange between precursors is ohserved and there is evidence for a CuO elching process.

Although the present MOCVD process is chemically complex, thin films of uniform composition over large areas can be readily grown. The conditions for the growth of $\mathrm{BaCaCuO}(F)$ lilms with 2:1:2 Ba:Ca:Cu cation stochiometry are shown in Tahle 1 . This simple reacur design aftords a uniform deposition rate of $20 \mathrm{~nm} / \mathrm{min}( \pm 5 \%$ measured thickness in a $16 \mathrm{~cm}^{2}$ area). Crystalline phases of $\mathrm{CaO}, \mathrm{Ba}_{2} \mathrm{CuO}$, and $\mathrm{BaF}_{2}$ are ohserved in the deposited thin films by $x$-ray diffaction. Due to the use of fluorine-containing metal-organic precursors. lluorides are readily incorporated into the film. To reduce the fluoride content, $\mathrm{H}_{2} \mathrm{O}$ is used in the oxidizer stream to huorides as volatile HF. To remove all fluorides in-situ, high deposition temperatures $(780)^{\prime C} \mathrm{C}$ ) are required. However, as described in the Tl-anneal section (see below), the fluoride content in the BCCO precursor film is not a critical factor, and deposition can be carried out at lower temperatures to enhance lïm morphology and to grow larger area films.

\subsection{Formation and characterization of $\mathrm{Tl}_{2} \mathrm{Ba}_{2} \mathrm{Ca}_{n-1} \mathrm{Cu}_{n} \mathrm{O}_{4+2 n}$ thin films}

The equilibrium pressure of $\mathrm{Tl}_{2} \mathrm{O}$ over bulk Tl-2223 at phase formation temperatures is near $10 \mathrm{Torr}$. 24] This relatively high pressure combined with the extreme reactivity of $\mathrm{Tl}_{2} \mathrm{O}$ renders an in-situ MOCVD process a daunting challenge. Therefore to form the TBCCO superconducting phases, the MOCVDderived $\mathrm{BaCaCuO}(\mathrm{F})(\mathrm{BCCO})$ precursor films are annealed over bulk TBCCO pellets, therchy providing the equilibrium $\mathrm{Tl}_{2} \mathrm{O}$ vapor pressure as in eq.(6). The subscripts of the reactant $\mathrm{Ba} \mathrm{Ca}_{\mathrm{n}-1} \mathrm{Cu}_{\mathrm{n}} \mathrm{O}_{\mathrm{x}(\mathrm{i} i \mathrm{~m})}$ refer to the cation stoichiometry $(\mathrm{n}=2,3)$, of the BCCO film.

$$
\begin{gathered}
\mathrm{Ba}_{2} \mathrm{Ca}_{n-1} \mathrm{Cu}_{n} \mathrm{O}_{\mathrm{x}(\mathrm{il} l \mathrm{ln})}+\mathrm{Tl}_{2} \mathrm{O}_{(\mathrm{g})} \longrightarrow \mathrm{Tl}_{2} \mathrm{Ba}_{2} \mathrm{Ca}_{n-1} \mathrm{Cu}_{11} \mathrm{O}_{4+2 n}(\mathrm{illm}) \\
\mathrm{Tl}_{2} \mathrm{O}_{3(\mathrm{~s})} \longrightarrow \mathrm{Tl}_{2} \mathrm{O}_{(\mathrm{g})}+\mathrm{O}_{2}
\end{gathered}
$$


This $\mathrm{Tl}_{2} \mathrm{O}$ pressure over the bulk pellet is strongly dependent on the annealing temperature and on pressure as is seen by the equilibrium in eq.(7). with higher $\mathrm{Tl}_{2} \mathrm{O}$ pressures achievahle at lawe: $\mathrm{O}_{2}$ pressures. The temperature required w form the Tl-2212 phase dereases markedly as $\mathrm{O}_{2}$ pressure is decreased. with Tl-2212 phase forming at $820 \pm 5^{\circ} \mathrm{C}$ and $895 \pm 5^{\circ} \mathrm{C}$ for $10 \%$ and $10 \mathrm{~km} \mathrm{O}_{2}$. respectively. The Tl-poor Tl-1212 phase is commonly seen outside of this range of conditions. That the $\mathrm{Tl}_{2} \mathrm{O}$ pressure control is key to TBCCO phase stability is strongly supported by the results of Aselage. of al. in twozone furnace experiments where $\mathrm{Tl}_{2} \mathrm{O}$ pressure is controlled. 24] It is important wo note that no tlumides are detected in annealed MOCVD films hy windowless EDX, Auger analysis, or XRD. BCCO precursu tilms grown at $50(1) \mathrm{C}$ contain negligible fluoride atter the Tl-anneal. The thuride is presumably remuve! during the anncal as TIF which is volatile and thermodynamically favored. [25]

To form the Tl-2223 phase, the BCCO precursor tilm is antealed over at $1: 2: 2: 3$ $\mathrm{Tl}_{2} \mathrm{O}_{3}: \mathrm{BaO}: \mathrm{CaO}: \mathrm{Cu}$ pellet in $10 \% \mathrm{O}_{2}$ at $820^{\circ} \mathrm{C}$ for $12 \mathrm{~h}$. Lower $\mathrm{O}_{2}$ pressures help to stathilize the gruwh of the Tl-2223 phase[26] and long annealing times (12h) are required. Films are shiny to the eyc, and the surface morphology is dominated by evidence of a melt during phase formation as shuwn in Figure $s$ Large platelets of $20 \mu \mathrm{m}$ dimensions and $500 \mathrm{~A}$ step heights, as measured by profilometry. are seen. A $\theta$ $2 \theta$ x-ray diffraction scan (Figure 9A) shows an essentially phase-pure T1-2223 sample.[27] Only th: (O)1) peaks are observed, indicating that the film is highly $\mathrm{c}$-axis oriented. The $\theta$-rocking curve (a further measure of $\underline{\underline{c}}$-axis orientation) exhibits a full width at half maximum of 0.8 " (Figure $9 B$ ) which is comparable to values for typical PVD-derived films. An in-plane $\phi$-scan (Figure $9 \mathrm{C}$ ) shows the relative orientation of the cell axes within the $\underline{-}$-plane. Reflections appear every $90{ }^{\circ}$ as expected for an epitaxial.
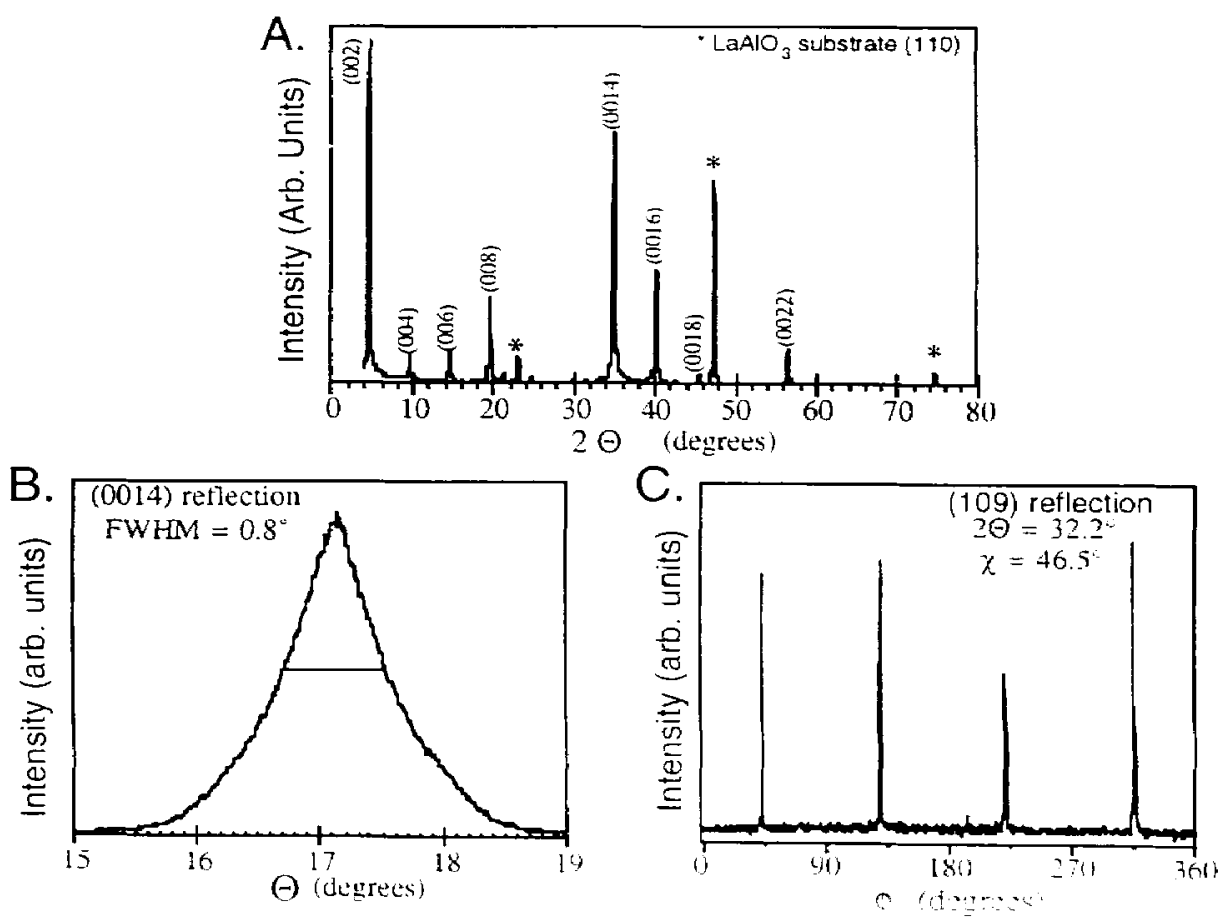

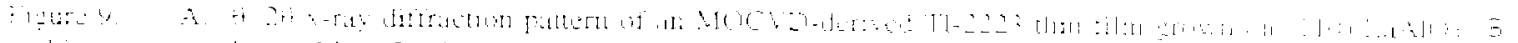

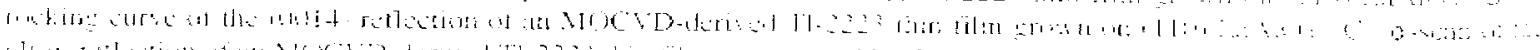

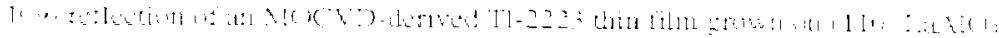


tetragonal TBCCO fïm.

Transport measurements provide further indications of film properties. The resistivity is. lemperature behavior of an MOCVD-derived Tl-2223 film (Figure I0A) indicates $T_{:}=115 \mathrm{~K}$. Several films were patterned using standard photolithography and EDTA exching lo deline an sil pm wide microbridge structure. Critical current density results from de and pulsed transport measurements appeu in Figure 10B. Al $77 \mathrm{~K}$, the highest $\mathrm{J}_{\mathrm{C}}=1.5 \times 10^{5} \mathrm{~A} / \mathrm{cm}^{2}$, as detined by a $10 \mu \mathrm{V} / \mathrm{cm}$ of tiset critcriun. Bean model calculations using SQUID susceptometer data yield $J_{c}=4 \times 106 \mathrm{~A} / \mathrm{cm}^{2}$ at $\left.5 \mathrm{~K}(0) \mathrm{T}\right)$ and $\left.6 \times 10\right)^{5}$ $\mathrm{A} / \mathrm{cm}^{2}$ at $77 \mathrm{~K}(0 \mathrm{~T})$. The $77 \mathrm{~K} \mathrm{~J}_{\mathrm{c}}$ values obtained from the transport and magnetic medsurements agrue reasonably well, suggesting that intragrain coupling does not adversely aftect the transpint cupucily of these lilms. These transport properties are comparable to those of the highest yuality PVD-derived iilms Figure $10 \mathrm{C}$ shows surface resistance measurements on a film containing some admixed $T 1-2212$ phast. performed in a parallel plate resonator against $\mathrm{YBCO}$. This measurement yields $\mathrm{R}_{\mathrm{s}}=11.35 \mathrm{~m} \Omega$ at $5 \mathrm{~K}$. 111 $\mathrm{GHz}$, approaching the lowest values reported for PVD-derived films. MOCVD-derived T1-2212 thin films are also of high quality with $T_{c}=105 \mathrm{~K}$, and $\mathrm{R}_{\mathrm{s}}=0.4 \mathrm{~m} \Omega(5 \mathrm{~K}, 10 \mathrm{GHz})$.

\subsection{Growth of dielectric oxide thin films}

Many advanced HTS devices require low dielectric loss, lattice-matched thin films for hutter layers or fur insulating layers in superconductor/insulator/superconductor (SIS) structures. Effïcien MOCVD griviti processes for these dielectric materials must be developed along with those for HTS materials. MOC VD has heen implemented in the growth of oxide systems such as $\mathrm{MgO}$ [28]. YSZ|29]. and CeO21301.
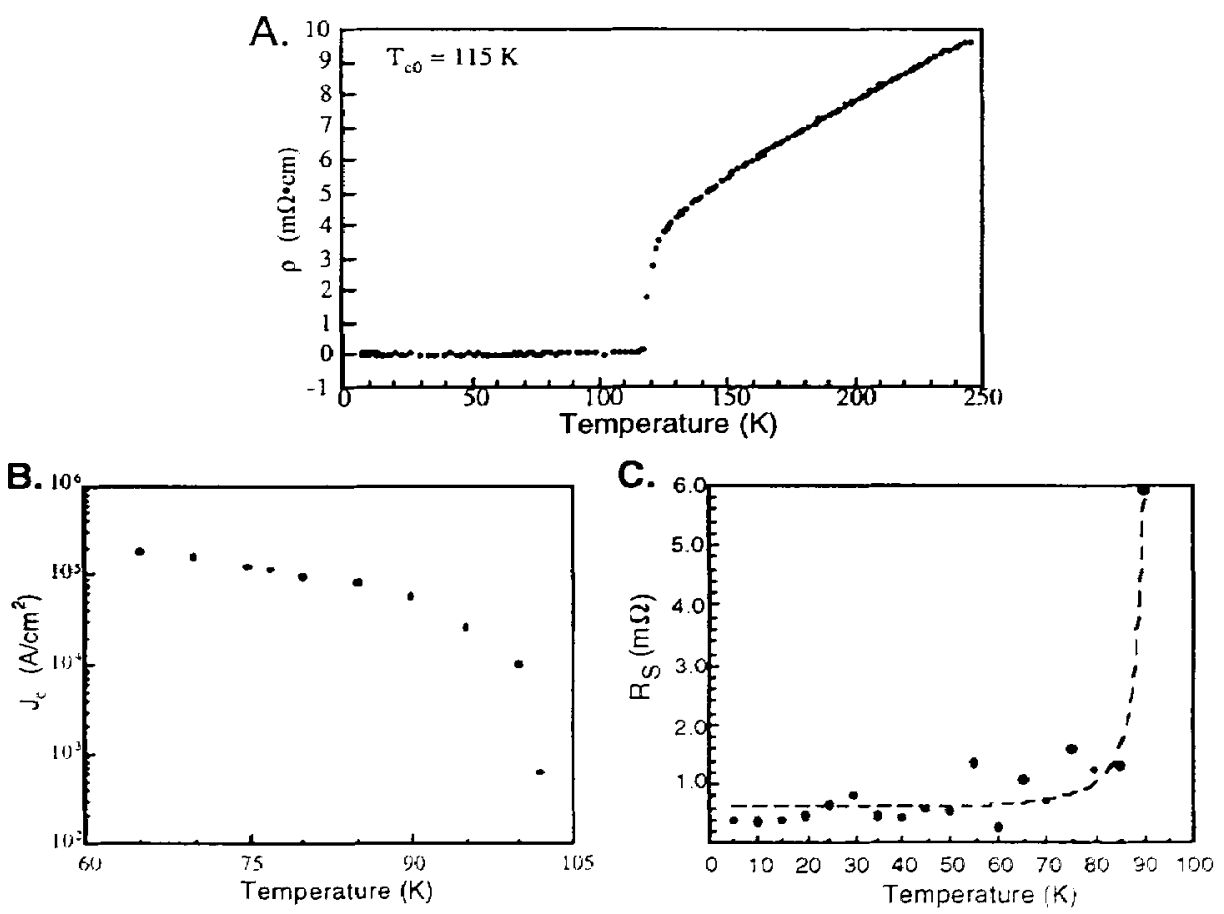

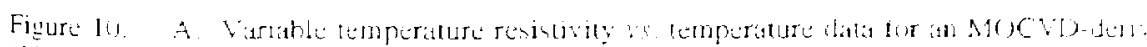

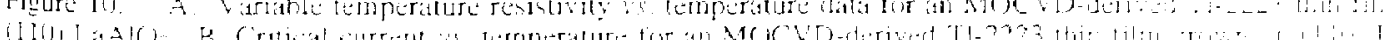

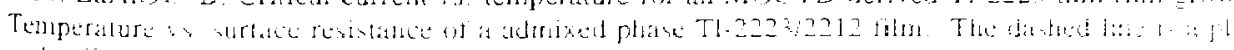

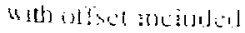


A.
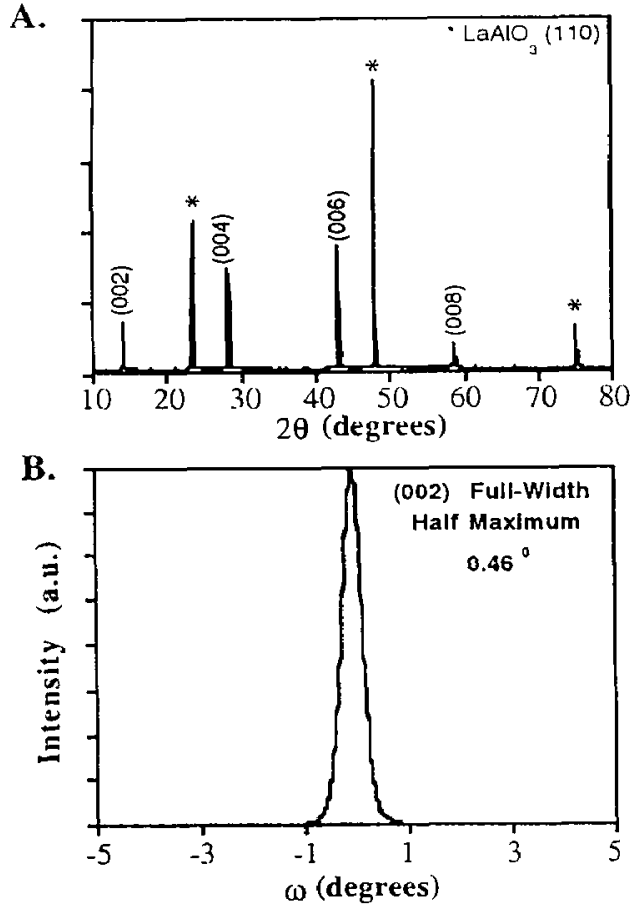

C.

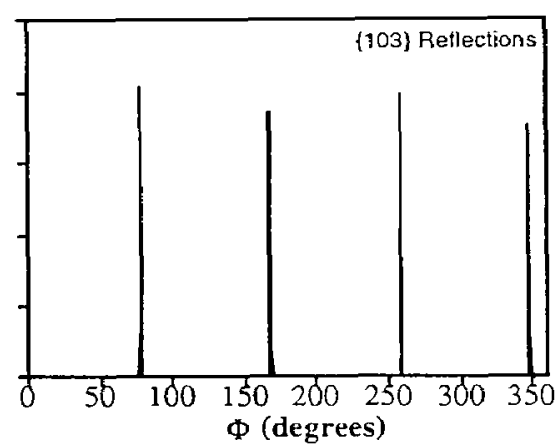

Figure 11A. $\quad \theta / 2 \theta$ XRD scan showing MOCVD derived (001) oriented $\mathrm{SrPrGaO}_{4}$ film grown on $\mathrm{LaAlO}_{3}$. B. $\theta$-rocking curve showing FWHM of $0.46^{\circ}$ for the $(002)$ reflection. C. $\phi$-scan showing in-plane epitaxy with the 4-fold symmetry of tetragonal $\mathrm{SrPrGaO}_{4}$.

of the in-plane scan demonstrate epitaxy (Figures $11 \mathrm{~B}-\mathrm{C}$ ).

Orthorhombic $\mathrm{PrGaO}_{3}$ films have also been grown on $\mathrm{LaAlO}_{3}$ by $\mathrm{MOCVD}$ using $\mathrm{Pr}(\mathrm{dpm})_{3}$ and $\mathrm{Ga}(\mathrm{dpm})_{3}$ at temperatures of $750-850^{\circ} \mathrm{C}$ with $\mathrm{N}_{2} \mathrm{O}$ as the oxidizer. Films are epitaxial hy XRD, hut the subtle (110) and (001) growth domains are again seen in TEM. However. hoth domains have nearly identical lattice spacings which are well-matched to YBCO (0.1\%). Onto this hullered substrate. epitaxial $\mathrm{YBa}_{2} \mathrm{Cu}_{3} \mathrm{O}_{7-x}$ films have grown by both pulsed laser deposition (PLD) and pulsed organometallic heam epitaxy (POMBE). Figures $12 \mathrm{~A}-\mathrm{C}$ shows XRD data demonstrating cpitaxial growth of YBCO by PLD on the MOCVD-derived epitaxial PrGaOz diclectric layet. Thi superconducting properties are excellent with $T_{C}=91 \mathrm{~K}$ and $J_{c}(77 \mathrm{~K})=6 \times 16 \mathrm{~A}^{6} \mathrm{~cm} \mathrm{~cm}^{2} .135 \mid$ This $(<1 \%)$ and greater chemical incrtness are of great interest.

Recent efforts in this lahoratory achicved the insitu epitaxial growth of $\mathrm{YAlO}_{3}$ lilms on $\mathrm{LaAlO}_{3}$ substrates using $Y(d p m)_{3}$ and $A /(\text { acac })_{3}$ as precursors.[31] A substrate temperature of $80(1)^{\circ} \mathrm{C}$ and $\mathrm{N}_{2} \mathrm{O}$ oxidizer gas were used Epilaxy is seen in the lourfold symmetry of the $\phi$-scan, and sharp intertaces are apparent in cross-sectional high resolution TEM. However, domains of (110) and (001) lilm growth are also seen by TEM (the rellections overlap in XRD experiments). The source of the $(110)$ and $(0) 1)$ domains is the close similarity in orthorhombic lautice parameters. To circumvent this, the growth ol cubic dielectrics has been investigaled. Thus, $\mathrm{Sr}_{2} \mathrm{AlT}_{21} \mathrm{O}_{6}$ films have been grown in-siru using Srothid) 2 let. $\mathrm{Al}(\mathrm{acac})_{3}$, and $\left[\mathrm{Ta}(\mathrm{OEL})_{5}\right]_{2}$ precursors with a substrato temperature of $850^{\circ} \mathrm{C}$ and $\mathrm{N}_{2} \mathrm{O}$ as the oxidizer. 32 Films are epitaxial by XRD analysis, and high resolutiom TEM shows no domain houndaries. Also of greal interest is tetragonal $\mathrm{LaSrGaO}_{+}$which, atong with close YBCO lattice and thermal expansion coctlicient match, has no phase transitions trom low temperature w $1520^{\circ} \mathrm{C}$, thus eliminating twinning. [33] Recently in this laboratory, thin films of the closely related compound. $\mathrm{SrPrGaO}_{4}$, have been grown for the first time on $\mathrm{LaAlO}_{3}$ by $\mathrm{MOCVD}$ using $\mathrm{Sr}(\text { h ha })_{2} \bullet$ tel, $\operatorname{Pr}(\mathrm{dpm})_{3}$, and $\mathrm{Ga}(\mathrm{dpm})_{3}$ precursors with $\mathrm{N}_{2} \mathrm{O}$ as the oxidizer al 810 C. [34] The XRD data shown in Figure I1 A indicate phase pure e-axis oriented $\mathrm{SrPrGaO}_{4}$ on $\mathrm{LaAlO}_{3}$. The sharp rocking curve and 4-fold symmetry

however materials with smaller HTS latlice mismatches 
A.
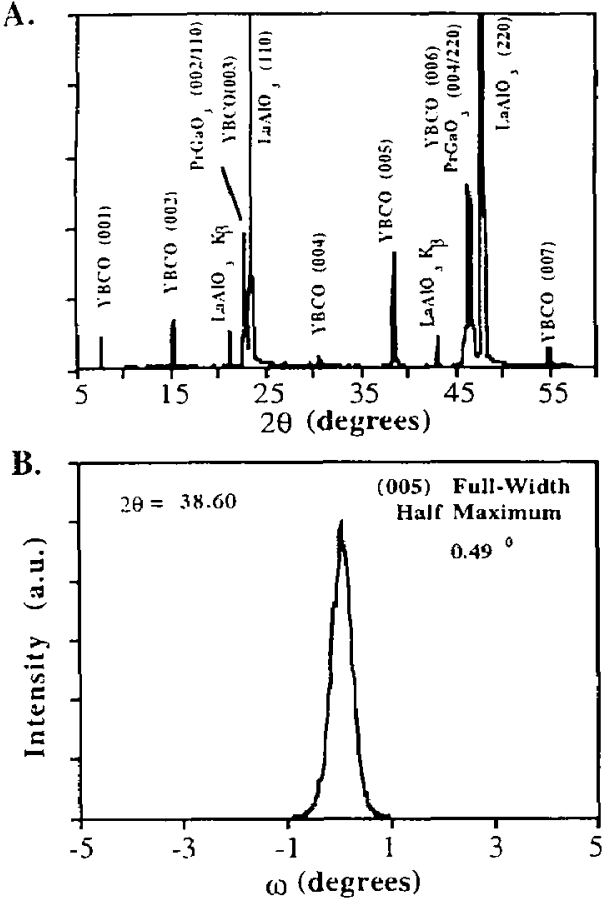

C.

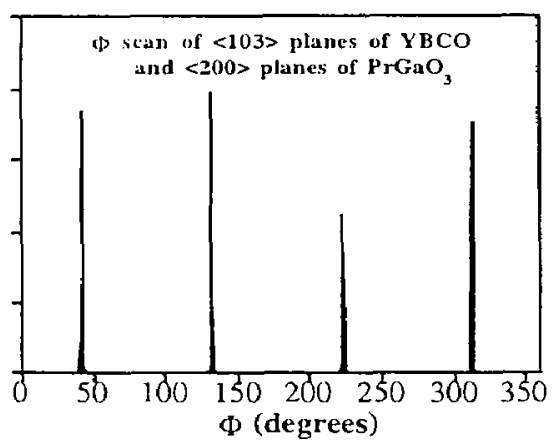

Figure 12A. $\theta / 2 \theta$ XRD scan showing a $\mathrm{YBCO} / \mathrm{PrGaO} / \mathrm{LaAlO}_{3}$ multilayer structure. B. $\omega$ rocking curve showing FWHM of $0.49^{\circ}$ for (005) retlection of $Y \mathrm{BCO}$ indicating high quality. C. $\phi$-scan showing in-plane epitaxy with the substrate for bots $\mathrm{YBCO}$ and $\mathrm{PrGaO}_{3}$. demonstrates that MOCVD can be effectively used in the growth of important diclectric/substrate lilms for HTS applications.

\section{CONCLUSIONS}

There has been significant progress in the development of MOCVD for HTS applications. Through carclul ligand design, volatile, thermally stable $\mathrm{Ca}$. Sr, and $\mathrm{B}$ a precursors are now available. In particular designed polyether adducts of thuorinated Ba complexes ate liquids under film growth conditions and thus exhihit stabie vapor pressure characteristics. For example, the liquid source, $\mathrm{Ba}(\mathrm{hfa})_{2} \bullet \mathrm{mep}$, has been implemented in the successful growth of TBCCO superconductu thin films. In the development of thurrine-free Ba sources, a novel complex has also been developed in which the polyether lariat is connected to $\beta$-kotuminate frameworks. In understanding the volatilization of HTS MOCVD precursors, a novel thermogravimetric analysis method has heen develuped. Information about both vapor pressure and vapor diflusion are obtained, and diffusion eflects are shown lo bo significant under typical MOCVD film growth conditions. $\mathrm{BaCaCuO}$ films are readily grown by MOCVD. The process is mass transter-limited at low temperatures (near $350^{\circ} \mathrm{C}$ ), and interesting ligand exchange processes are detected. High quality Tl-222.3 and 2212 films are formed from $\mathrm{BaCaCuO}(\mathrm{F})$ films annealed in the presence of $\mathrm{Tl}_{2} \mathrm{O}$ diffusing liom bulk TBCCO pellets at 820-895"C. Film transport properties are comparable to those of the hest PVDderived films with $T_{c}$ values as high as $115 \mathrm{~K}$ and surface resistances as low as $0.35 \mathrm{~m} \Omega$ at $5 \mathrm{~K}(1)(\mathrm{GH} \%)$.

MOCVD routes to dielectric oxide films have also been realized with epitaxial $\mathrm{YAlO}_{3}$. SI2 $\mathrm{AlTaO}_{6}$. $\mathrm{SrPrGaO}_{4}$, and $\mathrm{PrGaO}_{3}$ growth demonstrated on $\mathrm{LaAlO}_{3}$. A multilayer structure has been liabricated with high quality epilaxial YBCO grown upon MOCVD-derived $\mathrm{PrGaO}_{3}$. In summary MOCVD has heen successfully used to grow high quality superconducting thin films and dielectic layers which are applicable to the fabrication of HTS-based devices. 


\section{Acknowledgments}

This research was supported by the National Science Foundation through the Science and Techmology Center for Superconductivity (Grant No. DMR 912000()), by the Northwestem Matcrials Research Center (Grant No. DMR 9120521), and by ARPA (Contract 91-C-0112).

\section{References}

[1] Geake. E. New Scientist, 1993, 137, 20.

[2] Hammond R.B., Hey-Shipton G.L., Mathaei G.L., IEEE Spectrum 30, (1993) 34

[3] Z.Z. Sheng. A.M. Hermann, Narure 332 (1988) 55.

[4] Neumayer D.A., Studebaker D.B., Hinds B.J., Stem C.L., Marks, T.J., Chem. Mater. 6 (1994) 878.

[5] Hinds B. J., Schultz D.L., Nuemayer D.A., Han B., Marks T.J., Wang.Y.Y., Dravid V.P.. Schindler J.L.. Hogan T.P. Kannewurf C.R., Appl. Phys Lett, 65(2), (1994) 213.

[6] Hinds, B. J., Marks T.J. . Contribution in Glocker D.A., Shah,S.I., Ed. Handbook of Thin Film Process Tec/htolog1: loP Publishing Inc: Philadelphia PA. In Press.

[7] H. Moffat, K.F. Jensen. J. Cnst. Growth, 77, 108 (1986).

18] Lyding L.W., Marcy H.O., Marks T.J., Kannewurf C.R., IEEE Trans Instrumt. Meas. 37 (1988) 76.

[9] Otlosson M., Anderson T., Carlsson J.O., Harsta A., Jansson U., Norling P., Niskanen K.. Nordhlad P.. Appl. Phvs. Let. 96 (1989) 2476.

[10] Wills L.A., Wessels B.W., Richeson D.S., Marks T.J.Appl. Phys. Let. 60 (1992) 4$]$

[11] Thompson S.C., Cole-Hamilion D.J., Gilliland D.D., Hitchman M.L., Barnes J.C.. Adv. Maler. Opt. Electron. 1 (19y2) 81.

[12] Timmer K.. Spee C.I.M.A. Mackor A., Meinema H.A., Speck A.L., van der Sluis P., Inorg Chim. Acta 190 (1991) 109.

[13] Malandrino G., Fragalá 1.L, Neumayer D.A., Stern C.L., Hinds B.J., Marks T.J., J. Mat. Chemt. 4(7) (1994) 1061.

[14] Nuemayer D.A., Studebaker D.S., Hinds B.J., Stern C.L., Marks T.J., Chem. Mater. $6(1994) 878$.

[15] Schulz D.L., Hinds B.J.. Neumayer D.A., Steru C.L., Marks T.J., Chem. Mater 5 (199.3) 1605.

[16] Studebaker D.S., Neumayer D.A., Stern C.L., Hinds B.J., Marks T.J. in preperation.

[17] Hannay N.B.. Treatise on Solid State Chemisury Volume 6A Surfaces (Plenum Press. New York, 1976) pp 165-238.

[18] Gardiner R., Brown, D.W., Kirlin P.S., Rheingold A.L., Chem. Mater. 3 (1991) 1053.

[19] Langmuir 1. Phys. Rey. II (1913) 329.

1201 Takahashi Y., Matsuzaki K., Ijjuna M., Fukada E., Tsukahiura S., Murakami Y., Maesono A.. . fpn. . . Appl.. Phys. 32 (1993) L875.

[21] Chou K., Tsai G., Thermochintica Acta, 240 (1994) 129.

[22] Schmaderer F.. Huber R., Oetzmann H., Wahl G., "Chemical Vapor Deposition of High-Te Superconductors". Topical Conterence on Materials Aspects of High-Temperature Superconductors, Garmisch-Patenkirchen, Germany. (DGM Infornationsgesellschaft, Oberursel Germany, 1991) 153.

[2.3] Lin W., Warren T.H., Nuzzo R.G., Girolami G.S., J. Am. Chem. Soc. 115 (1993) 116.34

[24] Aselage T.L., Venturini E.L., van Deusen S.B., J. Appl. Phys. 75 (1994) 1023.

[25] Holstein W.L., Mat. Res. Soc. Symp. Proc., 335 (1994) 165.

[26] Lee W.Y., Garrison S.M., Kawasaki M., Venturini E.L., Ahn B.T., Boyers R., Appl. Phys. Letl. 60 (1992) 772.

[27] Hinds B. J., Schultz D.L., Nuemayer D.A., Han B., Marks T.J., Wang, Y.Y., Dravid V.P., Schindler J.L., Hogaun T.P., Kannewurf C.R., Appl. Phys Lett, 65(2) (1994) 213.

[28] Huang R., Kitai A.H., Appl. Phys Lett, 61 (1992) 1450.

[29] Holzschuh H., Suhr H., Appl. Phys Lett, 59 (1991) 470.

[30] Becht M., Gerfin T., Dahmen K.H. Chem. Mater. 5 (1993) 137.

[31] Han B., Neumayer D.A., Schulz D.L., Hinds B.J., Marks T.J., Chem. Mater. 5 (1993) 14.

[32] Han B., Neumayer D.A., Goodreau B.H., Marks T.J., Zhang H., Dravid V.P., Chem. Mater. 6 (1994) 18

[33] Hontsu S., Ishii J., Kawai T., Kawai S., Appl. Phys. Lett., 59(22) (1991) 2886.

[34] Chen J., Studebaker D.S., Marks T.J. in preperation.

[35] Han B., Neumayer D.A., Marks T.J., Rudman D.A., Zhang H., Dravid V.P., Appl. Phys Lett, 63 (1993) 36.39. 